\title{
Low-Ash Solid Fuel from Sewage Sludge: An Acid Extraction Method (Progress Report)
}

F. E. Senftle, P. Hackney, F. Jackson

A. Parker, K. Miller and Z. Brown

U. S. Geological Survey Open File

Report No. $88-239$

This report is preliminary and has not been edited or reviewed for conformity with Geological Survey standards or nomenclature. 
Many organic compounds can be protonated in concentrated sulfuric acid and thereby rendered soluble. If such solutions are diluted with water, the same compounds become deprotonated and subsequently precipitate. If the dilution is limited, much of the inorganic ash-forming compounds remain soluble in the diluted acid. Thus, protonation followed by dilution is a method of separating a low ash organic fraction from the sewage sludge. The product recovered can be used as a fuel, and is composed in part of secondary organic compounds formed by reaction with the acid.

This report describes preliminary results of experiments designed to recover an organic fraction from sewage sludge that can be used as a fuel. In the process, the insoluble organic fraction may also be separated and used for fuel blending or as a source of organic chemicals. A significant fraction of the inorganic insoluble component of the sewage sludge can also be recovered and processed as a source of some metals, such as titanium, that may be in sufficient concentration to be economically extracted. 


\section{INTRODUCTION}

Municipal governments all over the world are facing an ever-increasing problem of sewage sludge disposal. After treatment, the solid fraction of the sludge is generally disposed in land fills, used for composting, or incinerated simply to reduce the volume as far as possible. ${ }^{1}$ Such uses, however, are environmentally undesireable and are rarely cost effective.

Although sewage sludge is currently considered an environmental problem, it can be viewed as an important renewable energy resource if properly exploited. Thermal energy recovery by direct combustion is possible, but because of the high ash content of dried sludge, it is not an efficient fuel. Production of fuel ofl and synthetic asphalt from sewage sludge by direct thermochemical reaction is currently being investigated and has met with some success. ${ }^{2-5}$ Bayer and Kutubuddin ${ }^{2}$ have developed a technique to obtain oil from sewage sludge by heating the dry sludge to $300-500^{\circ} \mathrm{C}$ in an oxygen free environment for about 30 minutes. The ofl product has a heat content of $37-42 \mathrm{MJ} / \mathrm{kg}$. Bridle and Campbe $11^{3}$ have repeated their work using Canadian sludges and confirm the formation of a straight chain hydrocarbon ofl having a high heating value, and relatively low ash.

Depending on 1 ts source, dried sewage sludge contains up to 40 percent ash. Bayer and Kutubuddin, by converting the sludge to an ofl, have been able to separate the ash that remains in the residual sludge, so that a low-ash fuel ofl with a high heating value can be produced. Alternatively, if a significant fraction of the organic material in the sludge can be dissolved, the solution removed from the residue, and the organic material reconstituted as a solid precipitate from the solution, then a low-ash solid product could be obtained which would be suitable as a fuel or as a source material for organic chemicals. The fact that domestic sewage sludge contains quantities 
of carbonaceous material which are comparable to that in low grade fossil fuels and generally can be procured at a negative cost is an added attraction for the use of sewage sludge as a viable source of fuel or organic chemicals.

A number of neutral or alkali treatment processes for sewage sludge or coal cleaning have been suggested ${ }^{4,5,7,8}$, however, as pointed out by Vasilakos and Clinton ${ }^{9}$, little consideration has been given to the potential benefits of acid systems. For instance, it has long been known that a wide variety of organic compounds, with the exception of aliphatic hydrocarbons, and some aromatic hydrocarbons and their halogen derivitives, can be protonated at 0 to $35^{\circ} \mathrm{C}$ and subsequently become soluble in concentrated sulfuric acid $(>96-98$ percent) $10,11,12$. In Liler's review of reaction mechanisms in sulfuric acid 12 he discusses the increase in the proton activity (decrease in the Hammett acidity function) from dilute to concentrated sulfuric acid. By simply diluting the concentrated acid solution of organic compounds the proton activity decreases, 1.e. protonation decreases, and therefore organic compounds previously dissolved by protonation will be precipitated.

In the above method the organic fraction of sewage sludge finally resides In (a) the insoluble residue, (b) the deprotonated precipitate formed by dilution, or (c) the filtrate. It is the purpose of this report to examine the reaction of sewage sludge with concentrated $\mathrm{H}_{2} \mathrm{SO}_{4}$ to see if a method can be developed to extract both the organic and inorganic fractions from these three sources.

\section{THEORETICAL BACKGROUND}

Sewage sludge contains a mixture of organic and inorganic compounds. The organic fraction contains both aromatic and aliphatic compounds ${ }^{6}$ other than the acid insoluble variety mentioned above. Thus, if nominally dry sewage sludge is put into concentrated $\mathrm{H}_{2} \mathrm{SO}_{4}(18 \mathrm{M})$, a fraction of the organic matter 
can be protonated and will dissolve. Moreover, the inorganic matter w111 elther react with the acid and produce soluble salts or will remain in the insoluble fraction. The combined insoluble organic and inorganic material in the residue can be separated by centrifuging or filtration. If the filtrate carrying the dissolved organic and inorganic matter is subsequent1y diluted (s $10 \mathrm{M}$ ) with a minimum of water, some of the organic and possibly a small amount of the inorganic matter will precipitate. This product should be lower in ash compared to the original sludge, but initially it was not clear what fraction of the original organic matter in the sludge could be recovered as a fuel using this technique. Undoubtedly, in addition to the protonated organic matter, the filtrate before dilution will contain a substantial amount of organic species which have been altered by hydrolyzation, esterification, sulfonation, etc. and also some metallic inorganic compounds. If the dissolved organic and inorganic species remaining in the diluted acid can be removed separately by chemical processes, a useful fuel or organic chemical source can be realized. It is also important to separate the organic and inorganic constituents from the insoluble residue. The organic fraction may be suitable as a fuel or a source of chemicals whereas the inorganic fraction may be a source of metals.

The solid matter of sewage sludge is a mixture of organic and inorganic compounds. When placed in concentrated sulfuric acid, any given component of the mixture either (1) protonates and subsequently dissolves, (2) reacts with the acid and dissolves, or (3) is inert to the acid or reacts to form insoluble products. It is pertinent to briefly examine each of these processes.

1 - Organic Protoylsis: In their review of the solvent properties of sulfuric acid, Gillespie and Robenson ${ }^{10}$ have pointed out that, because of its 
protolytic characteristics, concentrated sulfuric acid is a much better solvent for many organic compounds compared with the other common mineral acids. Concentrated sulfuric acid (100 percent) in some ways resembles water as a solvent in that it self-protonates. Sulfuric acid has the largest autoprotolysis constant, and exhibits significant basic as well as strong acidic characteristics. Thus,

$$
2 \mathrm{H}_{2} \mathrm{SO}_{4}=\mathrm{H}_{3} \mathrm{SO}_{4}^{+}+\mathrm{HSO}_{4}^{-} ; \mathrm{K}=2.4 \times 10^{-4} \text { at } 25^{\circ} \mathrm{C}
$$

where $\mathrm{H}_{3} \mathrm{SO}_{4}{ }^{+}$and $\mathrm{HSO}_{4}{ }^{-}$are the principal acid and basic lons respectively. Although $\mathrm{H}_{3} \mathrm{SO}_{4}^{+}$and $\mathrm{HSO}_{4}{ }^{-}$are the principal ions, there are minor amounts of other Ionic species ${ }^{10,12}$, such as $\mathrm{HS}_{2} \mathrm{O}_{7}^{-}$and $\mathrm{H}_{3} \mathrm{O}^{+}$. When certain organic compounds are placed in a highly protonating solvent, the hydrogen ion from the protonating species $\left(\mathrm{H}_{3} \mathrm{SO}_{4}{ }^{+}\right)$will donate a $\mathrm{H}^{+}$ion causing the organic species to become charged. As pointed out by Gillespie and Robenson this is particularly true if the organic molecule contains basic groups or atoms in such a position in the molecule that admits easy protonation. They point out that organic substances with atoms contalning one or more pairs of unshared electrons, such as $0, \mathrm{~N}, \mathrm{~S}$ or $\mathrm{P}$, will protonate in concentrated $\mathrm{H}_{2} \mathrm{SO}_{4}$, be converted to its conjugate acid, and will dissolve. If any organic compound that can be protonated is designated (Org), then,

$$
(\mathrm{Org})+\mathrm{H}_{2} \mathrm{SO}_{4}+(\mathrm{Org}) \mathrm{H}^{+}+\mathrm{HSO}_{4}^{-}
$$

Precipitation of the organic compound without chemical change can be brought about by simply diluting the acid solution with a small amount of water. To minimize secondary reactions taking place at higher temperatures, the acid 
solution is gradually mixed with water to dissipate the heat or poured over ice. 12 When concentrated sulfuric acid is diluted the water undergoes almost complete ionization. Thus,

$$
\mathrm{H}_{2} \mathrm{SO}_{4}+\mathrm{H}_{2} \mathrm{O}=\mathrm{H}_{3} \mathrm{O}^{+}+\mathrm{HSO}_{4}^{-} ; \mathrm{K} \simeq 1 \text { at } 25^{\circ} \mathrm{C}
$$

However, if a protonated organic species is present in the sulfuric acid, dilution will cause deprotonation and subsequent precipitation of the organic species. Thus,

$$
(\mathrm{Org}) \mathrm{H}^{+}+\mathrm{HSO}_{4}^{-}+\mathrm{H}_{2} \mathrm{O}+\mathrm{Org}++\mathrm{H}_{3} \mathrm{O}^{+}+\mathrm{HSO}_{4}^{-}
$$

If the dilution is 1 imited (e.g. $1: 1$ ), the solution remains acidic enough to keep most of the inorganic components in solution, it is possible to remove some of the deprotonated organic materials relatively free of inorganic ashforming compounds. For example if ethyl amine were a compound in sewage sludge, then in concentrated sulfuric acid, ethyl amine will be protonated as follows,

$$
\mathrm{C}_{2} \mathrm{H}_{5} \mathrm{NH}_{2}+\mathrm{H}_{2} \mathrm{SO}_{4}+\mathrm{C}_{2} \mathrm{H}_{5} \mathrm{NH}_{3}^{+}+\mathrm{HSO}_{4}^{-} \text {, }
$$

and can be recovered by dilution leaving most the ash forming inorganic components of the sludge dissolved in the acid solution. It is important to note that protolysis is a very rapid mechanism because of the high mobility of . $\mathrm{H}_{3} \mathrm{SO}_{4}^{+}$and $\mathrm{HSO}_{4}^{-}$stemming from the proton-transfer process. 2-Organic Reactions: Gillespie and Leisten ${ }^{13}$ and more recently Liler ${ }^{12}$ have reviewed many of the possible reactions with sulfuric acid. For instance, some of the organic constituents of sewage sludge will undergo sulfonation by 
forming hydrogen bonds with sulfuric acid and acid soluble salts. For example, some alcohols can be sulfonated. Thus,

$$
\mathrm{ROH}+2 \mathrm{H}_{2} \mathrm{SO}_{4} \rightarrow \mathrm{RHSO}_{4}+\mathrm{H}_{3} \mathrm{O}^{+}+\mathrm{HSO}_{4}^{-}
$$

When an acidified solution of sewage sludge is diluted to remove the organic protonated constituents, a significant fraction of the compounds formed by reaction with $\mathrm{H}_{2} \mathrm{SO}_{4}$ may also precipitate from solution. As these compounds contain sulfur, it is desirable to reduce the sulfonated components of the precipitate to a minimum. Depending on the extent of the dilution a substantial fraction of the total dissolved organic matter may remain in solution. These organic compounds can be removed by further dilution or by chemical treatment.

3 - Inert materials: Although there are many organic compounds in sewage sludge which will dissolve in concentrated $\mathrm{H}_{2} \mathrm{SO}_{4}$, there are some organic compounds that are insoluble. Among these are the paraffins, benzene, naphthalene, and the alkyl and aryl halides. In addition to these compounds, silica and some of the inert inorganic constituents will remain in the residue. Because of the relatively high density of the acid solution, that fraction of the residue containing a high concentration of organic matter will float and the more dense part of the insoluble residue containing a large fraction of inorganic material will sink. Organic- and inorganic-rich fractions can thus be separated. The inorgantc fraction of the residue may be rich enough in some of the heavy metals to warrent further extraction depending on the kind and concentration of metals present, and on the source of the sludge. 


\section{SOURCE AND PREPARATION OF SAMPLES}

To determine if protonation of sewage sludge can be used to extract an organic product that may be suitable as a fuel, a preliminary investigation of the technique and the determination of some of the physical and chemical characteristics of the product was made. The sewage sludge samples used in these experiments were collected from the Blue Plains Sewage Treatment Plant in Washington, D.C., and were selected from different points in the treatment process designated as follows:

a. Dewatered primary sludge blended with secondary sludge (processed sludge from vacuum filters with added $\mathrm{FeCl}_{3}$ and lime for coagulation, and a polymer for dewatering). This sample contained 2.35 percent water.

b. Raw primary sludge from gravity thickener to which $30 \mathrm{mg}$ of $\mathrm{FeCl}_{3}$ was added per liter for coagulation. This sample was dewatered only to 95.23 percent, and was used to prepare samples "c" and " $d$ " by removal of additional water.

c. Same as sludge "b", but centrifuged to reduce the water content to 68.8 percent.

d. Same as sludge "b", but further dewatered to 6.15 percent water.

e. Biological sludge which was dewatered to $\simeq 6$ percent water.

f. Raw primary sludge from gravity thickener to which waste pickle liquor (ferrous sulfate) was added for coagulation. The original sample contained 93.38 percent water and was dewatered to 2.61 percent water.

The first experiments were made using samples " $a$ " through " $e$ " within a few weeks after collecting the samples. Several months later some repeat experiments were made with portions of the same samples before dewatering, but it was noted that the chemical composition had changed significantly due to microbial action. Sample "f", collected several months after obtaining 
samples a to e, was dewatered to 2.61 percent moisture within a few days after collection to reduce microbial activity to a minimum.

The total solids and moisture of the sludge samples were determined by drying 20 to 25 grams of the raw wet sludge for 12 to 24 hours at $103^{\circ} \mathrm{C}$ in an air circulation oven. To determine the ash content, the samples were ignited at $550^{\circ} \mathrm{C}$ in air for a minimum of 60 minutes to oxidize and remove the organic material (volatiles). This procedure is subject to a small error due to the decomposition of some inorganic constituents such as ammonium carbonate. This error has been ignored because of the small amount of such compounds in the sewage sludge used. The total solids, molsture, ash, and volatiles are given in Table I. The chemical composition of the total solids is presented in Table 2.

\section{INITIAL EXPERIMENTS}

Initially a number of exploratory experiments were made to see if the sludge material could be dissolved in concentrated acid, * if the ash could be reduced substantially, and if the heating value of the product was enhanced over the original sludge sample. The extraction and recovery of the organic material from the sludge generally followed the flow diagram down to product G (see Figure 1). The sludge sample (2-50 g) was gradually reacted with an excess of concentrated $\mathrm{H}_{2} \mathrm{SO}_{4}$ either at room temperature or in some experiments with the acid at $468 \mathrm{~K}\left(195^{\circ} \mathrm{C}\right)$. The sludge and acid formed a viscous black solution and a residue. Some heat was evolved due to dilution of the acid with moisture in the sludge, but this was minimized by slowly adding the acid so that the temperature did not rise more than about 10 degrees. In later

* Although the previous discussion applies to 100 percent $\mathrm{H}_{2} \mathrm{SO}_{4}$, we refer to concentrated acid as $96-98$ percent. This reagent is not as good a protonating agent as 100 percent $\mathrm{H}_{2} \mathrm{SO}_{4}$, but it is a more realistic strength to use for a commerical process. 


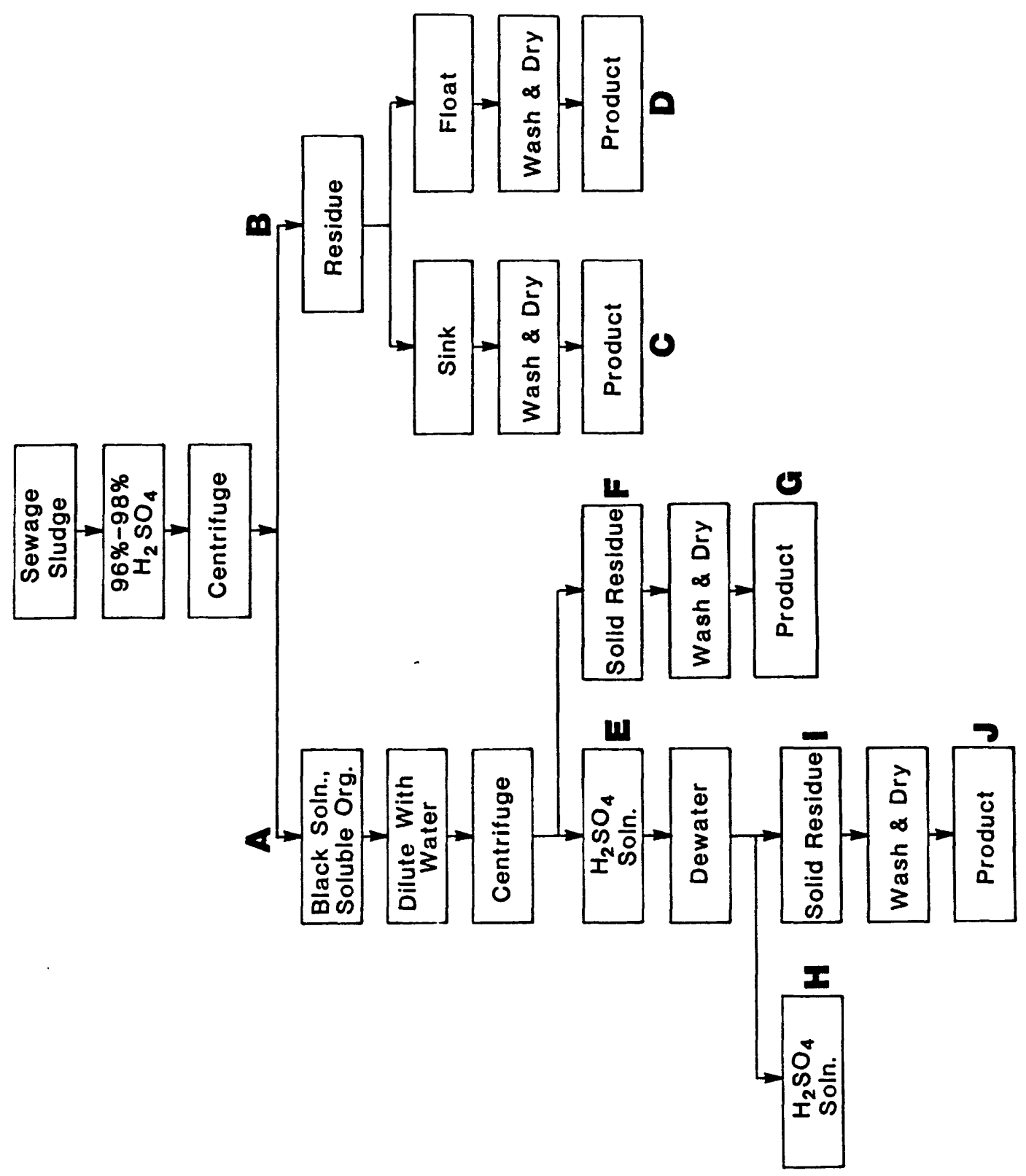

8.1 
TABLE 1. Total solids, moisture, ash, and volatiles in the sewage sludge samples

Sewage Sludge Sample Designation

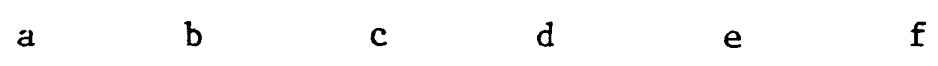

$\begin{array}{lrrrrrr}\text { Total Solids, \% of sample } & 97.65 & 4.77 & 31.15 & 93.85 & 94.00 & 97.39 \\ \text { Moisture, \% of sample } & 2.35 & 95.23 & 68.85 & 6.15 & 6.00 & 2.61 \\ \text { Ash, \% of Total Solids } & 63.08 & 27.92 & 27.92 & 27.92 & 49.89 & 18.56 \\ \text { Volatiles, \% of Total Solids } & 36.92 & 72.08 & 72.08 & 72.08 & 50.11 & 81.44\end{array}$


TABLE 2. Composition, H/C atom ratio, and heating values of total solids in sewage sludge samples.

Sample No.

Weight Percent Composition

$\mathrm{H} / \mathrm{C} \quad$ Heating Value

$\begin{array}{lllllll}C & \mathrm{H} & \mathrm{N} & \mathrm{S} & \mathrm{O}^{1} & \text { Ash } & (\mathrm{MJ} / \mathrm{kg})^{2}\end{array}$

$\begin{array}{lllllllll}\text { a } & 21.6 & 3.1 & 2.9 & 0.23 & 9.10 & 63.08 & 1.72 & 10.2 \\ \text { b } & 40.8 & 5.8 & 3.9 & 0.25 & 21.31 & 27.92 & 1.70 & 18.3 \\ \text { c } & 40.8 & 5.8 & 3.9 & 0.25 & 21.31 & 27.92 & 1.70 & 18.3 \\ \text { d } & 40.8 & 5.8 & 3.9 & 0.25 & 21.31 & 27.92 & 1.70 & 18.3 \\ \text { e } & 23.7 & 3.4 & 3.8 & 0.28 & 18.84 & 49.89 & 1.74 & 9.6 \\ \text { f } & 46.1 & 6.5 & 3.2 & 1.04 & 24.60^{3} & 18.57 & 1.68 & 20.6\end{array}$

1 Calculated by difference. Values may be up to a few percent high due to presence of small amounts of other elements such as phosphorus.

2 Heating Values should be slightly higher because of oxygen approximation. See note *.

3 Chemical analysis. 
experiments a water bath was used to keep the sample cool. After reacting for a given time, the black solution was filtered through a glass filter (Whatman No. 934-AH) to remove the undissolved residue, "B", (see Figure 1). The black filtrate, "A", was slowly mixed into $250-350 \mathrm{~mL}$ of distilled water forming a black precipitate in the solution. The combined diluted acid solution and the precipitate were centrifuged and the lightly colored dilute acid solution, E, was poured off. The precipitate, F, was then washed and centrifuged 1 or 2 times with distilled water to remove the excess acid from the precipitate. Further washing with distilled water resulted in some loss of the precipitate by peptization. Attempts to neutralize the acid by washing with dilute $\mathrm{NH}_{4} \mathrm{OH}$ solution also resulted in loss of the product. For this reason the precipitates in this initial series of experiments were not thoroughly washed. As the final pH of the wash water did not rise above 2 or 3 , the final products had unacceptably large sulfate concentrations. The washed precipitate or product, G, after drying, was a dull black substance which was slightly soluble in water, concentrated sulfuric acid, benzene, acetone, carbon tetrachloride and alcohol.

The conditions for each experiment are given in Table 3 . In these experiments a large excess of acid was used to ensure that the acid was not unduly diluted by the water in the samples. As no effort was made to make a quantitative extraction, the amount of organic material recovered is relatively small, and, should not be used to evaluate recovery of the product. The analyses of the organic products are given in Table 4. Carbon, hydrogen, nitrogen and sulfur were analyzed by combustion analysis. Some analyses of oxygen were also made but, as the sum of the concentration of other unaccounted for elements present in the sludge is but a couple percent, an approximate oxygen concentration was determined by difference. Ash 
TABLE 3. Experimental Parameters

$\begin{array}{cccccc}\text { Sample and } & \text { Wet Sludge } & \text { Total Solids } & \text { Reaction } & \text { Reaction } & \text { Dry Product } \\ \text { Experiment } & \text { Reacted } & \text { to Acid Wt. } & \text { Temperature } & \text { Time } & \text { Recovered } \\ \text { No. } & \text { (gms) } & \text { Ratio } & & \text { (min) } & \text { (gms) }\end{array}$

Acid Extraction Products (AEP)

$\begin{array}{lrllrl}\mathrm{a}-1 & 2.5 & 1: 46 & 468 \mathrm{~K}\left(195^{\circ}\right) & 0.5 & 0.359 \\ \mathrm{~b}-1 & 51.0 & 1: 46 & 468 \mathrm{~K}\left(195^{\circ} \mathrm{C}\right) & 5 & 0.193 \\ \mathrm{c}-1 & 20.0 & 1: 35 & 468 \mathrm{~K}\left(195^{\circ} \mathrm{C}\right) & 20 & 1.12 \\ \mathrm{c}-2 & 20.0 & 1: 35 & 298 \mathrm{~K}\left(25^{\circ} \mathrm{C}\right) & 20 & 0.38 \\ \mathrm{~d}-1 & 6.64 & 1: 35 & 373 \mathrm{~K}\left(100^{\circ} \mathrm{C}\right) & 20 & 1.80 \\ \mathrm{~d}-2 & 3.32 & 1: 35 & 298 \mathrm{~K}\left(25^{\circ} \mathrm{C}\right) & 5 & 0.13 \\ \mathrm{e}-1 & 12.75 & 1: 44 & 298 \mathrm{~K}\left(25^{\circ} \mathrm{C}\right) & \simeq 6 & 0.60\end{array}$


$\stackrel{\frac{0}{3}}{\frac{3}{3}}$

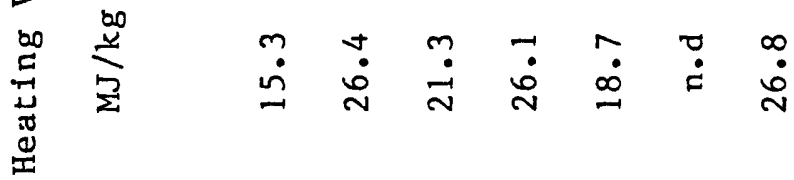

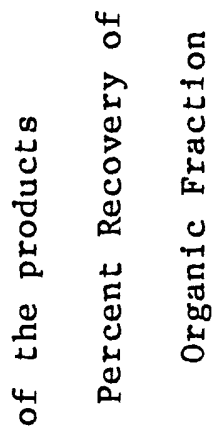

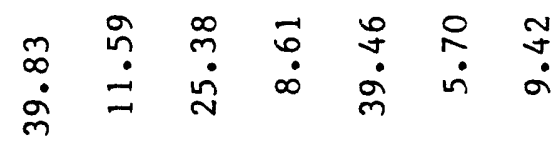

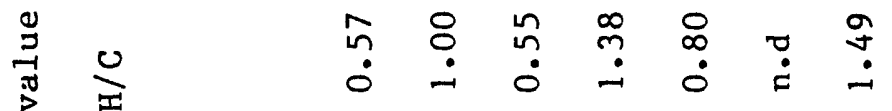

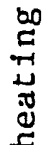

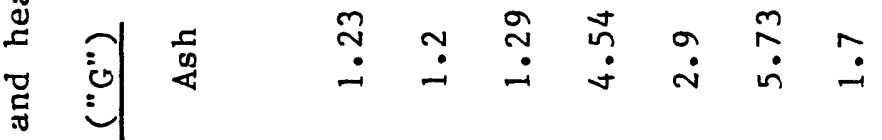

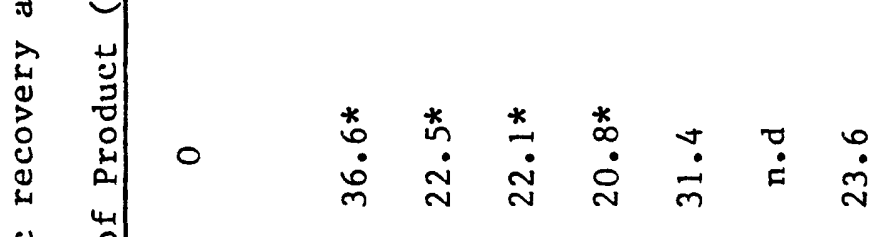

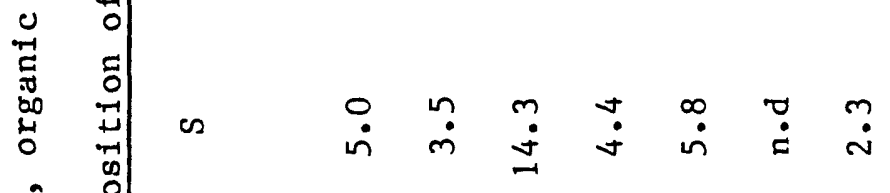

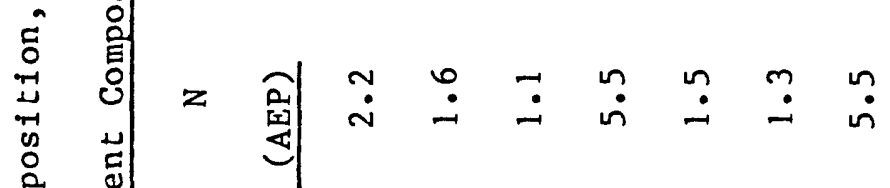

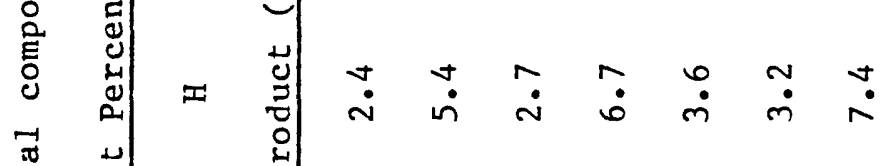

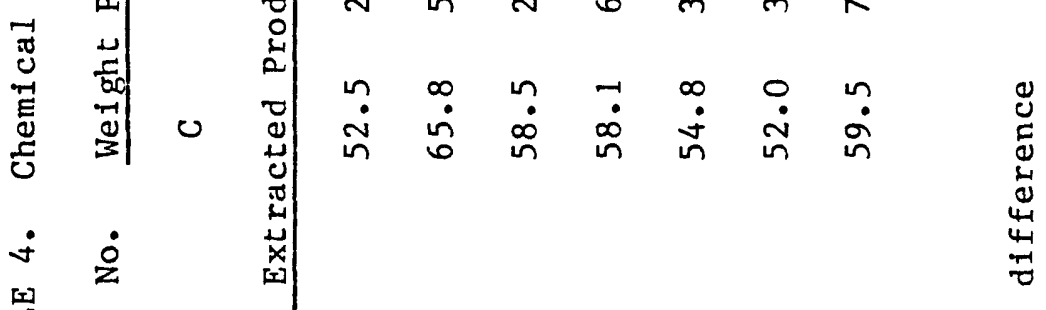

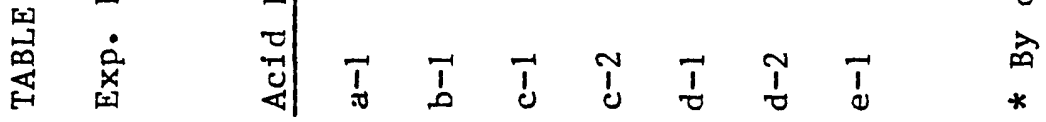


residues were determined as described for the sewage sludge above. It was assumed that when the sludge or products were heated to $550^{\circ} \mathrm{C}$ in air, essentially all of the carbonaceous material was converted to $\mathrm{CO}_{2}, \mathrm{H}_{2} \mathrm{O}$ etc. and removed from the sample as volatiles. The heating values were calculated from a modified Dulong formula given by Giazzi and Columbo ${ }^{13}$.

From these initial experiments a few general observations can be made.

1. There was an increase in the heating value of the product compared to the dried sludge.

2. In all cases there was a decrease in the ash content of the product compared to the original sludge.

3. The H/C ratio of the product, which roughly reflects the ratio of aromatic to aliphatic components, was lower than in the initial sludge, and also more variable from sample to sample.

4. The sulfur concentration was larger than in the initial sludge samples, probably due in part to incomplete washing, or chemical sulfonation.

Because the results depend on several parameters which were not sufficiently controlled in the initial experiments, only the few general conclusions mentioned above can be drawn. Therefore additional experiments were made to evaluate the more critical parameters.

\section{LATER EXPERIMENTS}

In a second series of experiments an effort was made to standardize the procedures. In all the experiments 3 grams of dried sludge sample "f" (2.61 percent moisture) were reacted with $100 \mathrm{~mL}$ of $\mathrm{H}_{2} \mathrm{SO}_{4}$ unless otherwise stated. Residue B: As shown in Figure 1, after the initial centrifuging, the residue B divided into a sink and float fraction due to the high density of the concentrated acid solution, A. Generally the float and sink fractions were combined and called residue B. Typically, the light fraction was composed of 
about 80-85 percent and the heavy fraction about 45-50 percent organic matter. Typical analyses of the organic part of the sink and float fractions ( $C$ and $D$ in Figure 1) are given in Table 5. Although the carbon is low and the sulfur is high, the organic material in both the heavy and light fractions of residue $B$ may have value as a low grade fuel, or as a source material for organic chemicals if it can be economically separated from the inorganic fraction.

Attempts were made to remove the organic matter from the residue $B$ by solvent extraction using several ordinary organic solvents, but the yields were poor. However, by reworking either or both the insoluble sink or float fractions with concentrated $\mathrm{H}_{2} \mathrm{SO}_{4}$ at higher temperatures (e.g. from $30-100^{\circ} \mathrm{C}$ ) additional organic material can be dissolved. At $180^{\circ} \mathrm{C}$ essentially all of the organic fraction of the sludge goes into solution. For further recovery of organic material from residue $B$ a detalled study should be made by heating the residue with concentrated $\mathrm{H}_{2} \mathrm{SO}_{4}$ at different temperatures up to about $100^{\circ} \mathrm{C}$. As discussed below, the additional organic material dissolved in hot $\mathrm{H}_{2} \mathrm{SO}_{4}$ and recovered by dilution will suffer some degradation in heating value because of oxidation, but if the loss in fuel value is minimal, it may be an economically feasible step. Alternatively, recovery by reworking at room temperature may be feasible to increase the yield of organic product. Further work in this direction is planned.

Effects of Dilution: A problem encountered in diluting solution A is the recovery of the insoluble precipitate $F$. Similar to the residue $B$, after dilution of solution A the product precipitate will float, sink, or simply remaln suspended in solution depending on the amount of dilution. A series of measurements were made to determine the density of the solution for different dilutions. As shown in Figure 2, the precipitate $F$ floated completely for a 


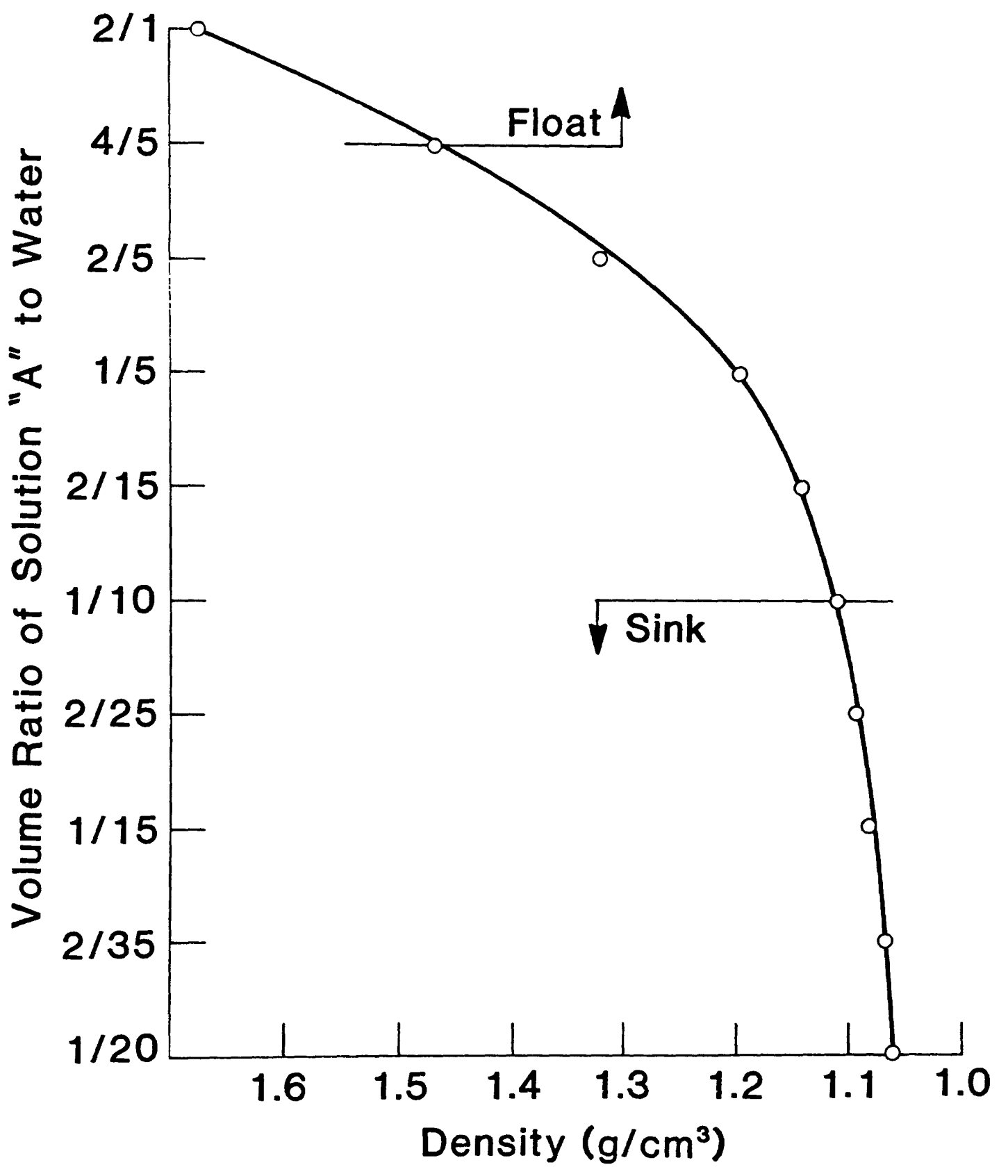

Fig Fig 2

11.1 
Table 5. Elemental concentrations (in percent) of the organic fractions of the sink and float residues (residue B) corrected to 100 percent organic material.

Sample No.

C

H

$\mathrm{N}$

S

0

F-R (float)

53.1

6.8

5.8

4.4

22.6

$S-R$ (sink)

56.42

7.19

8.39

2.19

27.39

lla 
dilution ratio of solution to water of 4:5 and sunk for ratios of less than 1:10. If the density is kept high by using the former ratio, the entire residue floats, and is relatively easy to recover. From a commercial point of view this method entalls less loss of acid by dilution and would be a favored technique. However, somewhat less organic product is recovered than with greater dilution. Alternatively, if the density is reduced by greater dilution, the entire residue sinks, and is also easy to remove. However in either case the residual acid cannot be removed except with considerable washing. Peptization takes place after repeatedly washing the product with water and leads to a significant loss of the product. To circumvent the problem of peptization when the product was washed in distilled water, some experiments were done using a concentrated sodium chloride wash solution. However, it was found just as difficult to remove the salt from the product as it was from the acid. To remove the residual acid, it was finally decided to thoroughly wash the product with water even though it meant sacrificing some product recovery. The problem of dilution and washing of the product requires additional work to determine the optimum conditions.

In the early experiments it was not clear what effect the degree of dilution of the solution "A" had on the product composition. An experiment was made at $25^{\circ} \mathrm{C}$ and also at $70^{\circ} \mathrm{C}$ in which the solution " $\mathrm{A}$ " was diluted successively with different amounts of water. In the experiment at $25^{\circ} \mathrm{C}$ a small amount of product precipitated on the first dilution with $75 \mathrm{~mL}$ of water (see Table 6). Five successive dilutions with $25 \mathrm{~mL}$ of water (total of 200 $\mathrm{mL}$ ) produced only a very small amount of additional product. However, when the solution was further diluted with an additional $25 \mathrm{~mL}$ of water (total of $225 \mathrm{~mL}$ ) a large amount of product precipitated. Further dilution produced substantially smaller amounts of product. In the experiment made at $70^{\circ} \mathrm{C}$ the 
results followed the same pattern except that the total amount of product precipitated was considerably larger. In some cases the product precipitated by dilution was washed with a salt solution to reduce peptization and the sample weight had to be corrected for the imcomplete removal of a small amount of salt.

The product composition did not vary significantly for those samples within either set of experiments made at the given temperatures (Table 6). However, there were significant differences in the composition of the samples obtained in the experiments at the high and low temperatures. The carbon, hydrogen and $\mathrm{H} / \mathrm{C}$ ratios are somewhat higher in the products formed at low temperature (excluding the two low temperature samples which were not corrected for a small residual $\mathrm{H}_{2} \mathrm{SO}_{4}$ concentration due to incomplete washing). Likewise, the concentrations of sulfur and oxygen were lower for the samples prepared at low temperature compared to those made at high temperature. It should be noted that the product obtained at room temperature on the first dilution ( $75 \mathrm{~mL}$ of water) could be ashed at a lower temperature compared to the product obtained by dilution with $225 \mathrm{~mL}$ of water. The lower temperature for ashing suggests that this material probably contained more volatile components, (i.e. it is a better fuel) compared to the product formed at greater dilution. These data also suggest that protonation is probably the principal mechanism at low temperature, whereas at the higher temperatures oxidation reactions occur with the $\mathrm{H}_{2} \mathrm{SO}_{4}$ forming sulfate esters, and other secondary reaction products. From the point of view of a fue1, is was also found that the heating value of the product extracted at low temperature was considerably better than that formed at temperatures of $70^{\circ} \mathrm{C}$ or higher. Temperature Effects: To determine the effects of temperature on the product in more detail a number of comparative experiments were made at several 


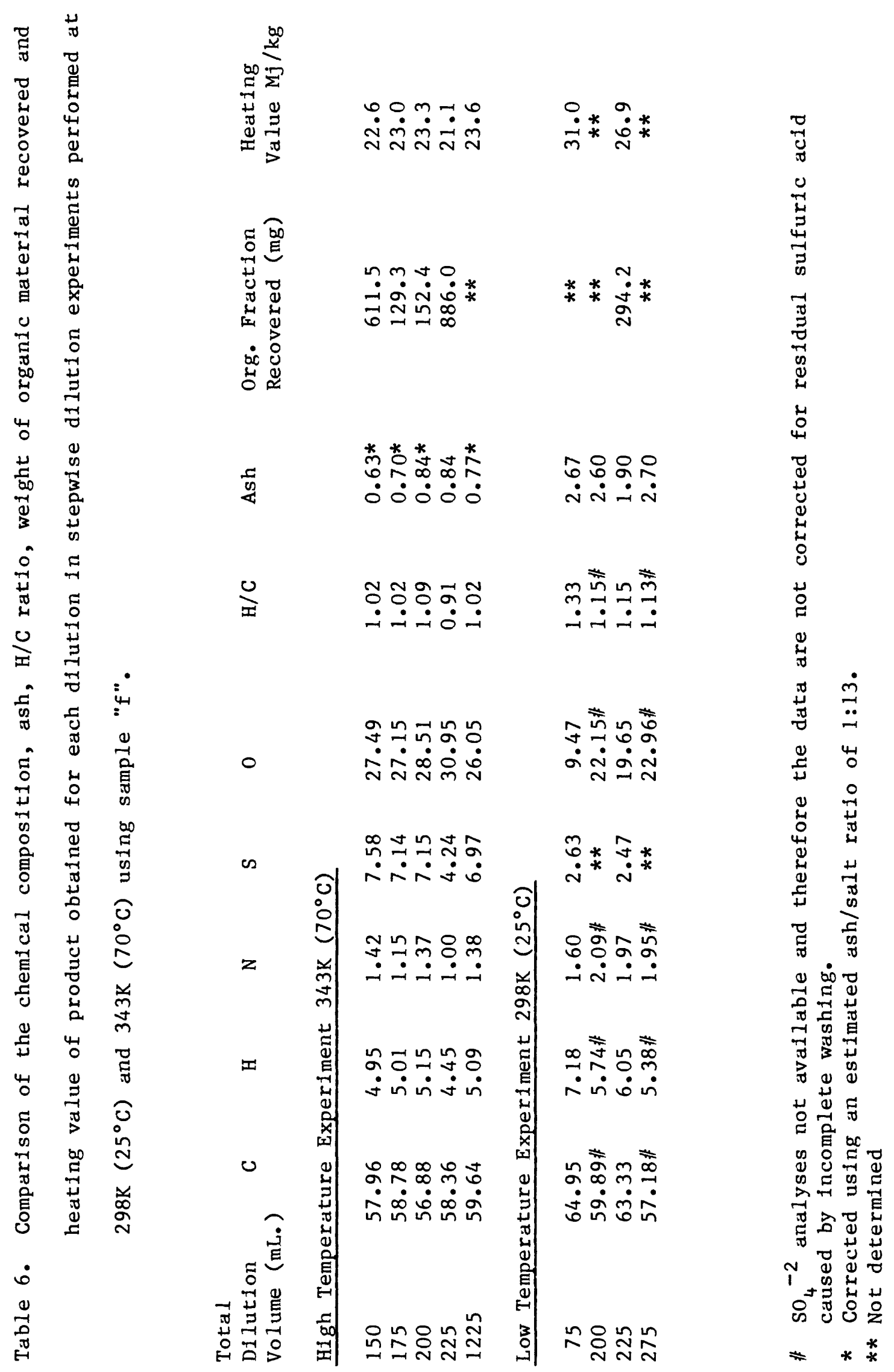


temperatures. The typical analyses of the products formed at three temperatures are shown in Table 7. The elevated heating value and lower sulfur concentrations result from extraction of organic matter at room temperature. The lower carbon concentration in the products obtained at the higher temperatures suggest the evolution of $\mathrm{CO}_{2}$ even at temperatures as low as $70^{\circ} \mathrm{C}$ although there was no visible signs of emission of gas during the experiments. Several additional experiments were made at various temperatures in a closed system, which was fitted with a liquid nitrogen cold trap to freeze out any $\mathrm{CO}_{2}$ gas emitted. At $135^{\circ} \mathrm{C}$ and above there was a significant production of $\mathrm{CO}_{2}$. Experiments at lower temperatures indicated that at about $80^{\circ} \mathrm{C}$ visible amounts of solid $\mathrm{CO}_{2}$ started to form in the trap. However, from the carbon analyses in Tables 6 and 7 , it appears that $\mathrm{CO}_{2}$ was probably evolved at temperatures as low or lower than $70^{\circ} \mathrm{C}$. Thus, above $70^{\circ} \mathrm{C}$ substantial oxidation takes place in the sludge. Effect of Reaction Time: To determine the effect of the time the acid is in contact with the sludge (reaction time) a separate series of experiments was made. Dried sludge " $\mathrm{f}$ " was reacted with $60 \mathrm{~mL}$ of concentrated $\mathrm{H}_{2} \mathrm{SO}_{4}$ for given time (30 min. to 24 hours) at $25^{\circ} \mathrm{C}$. The mixture was then centrifuged for 8 minutes at about $3500 \mathrm{rpm}$. The total time of exposure to the acid plus 8 minutes for centrifugation is considered the total reaction time. The black acid solution (solution A) was poured off leaving the insoluble residue (residue B) (combined sink and float fractions). The residue was washed, dried, weighed and ashed. The solution A was diluted with $750 \mathrm{~mL}$ of water which formed a precipitate which was washed and dried forming product G (Figure 1). The product was also ashed. This experiment was repeated for five different reaction times.

The results in Table 8 show that, while the total amount of residue 


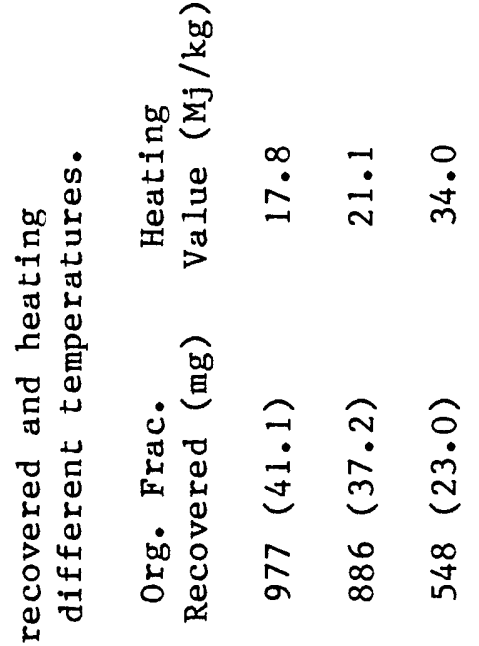

$$
\begin{aligned}
& \text { 牙苛 }
\end{aligned}
$$

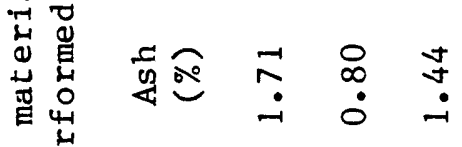

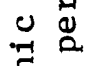

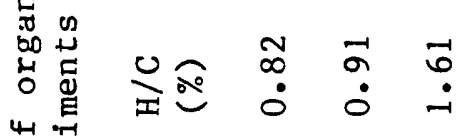

$$
\begin{aligned}
& \text { 㟧 면 }
\end{aligned}
$$

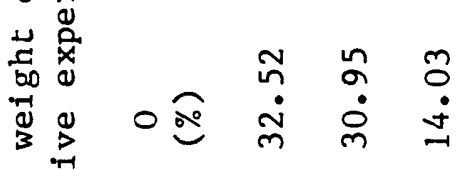

$$
\begin{aligned}
& 0+\frac{1}{0} \\
& \text { 年 }
\end{aligned}
$$

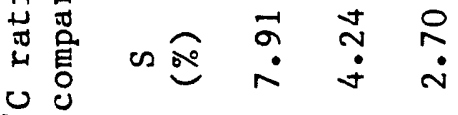

$$
\begin{aligned}
& \text { i工 }
\end{aligned}
$$

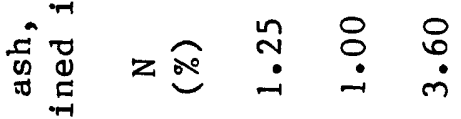

$$
\begin{aligned}
& \text { 起苔 }
\end{aligned}
$$

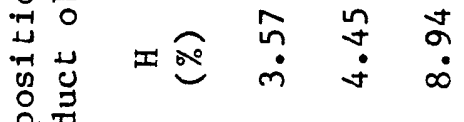

$$
\begin{aligned}
& \text { 苜雚 } \\
& \text { 苞 }
\end{aligned}
$$

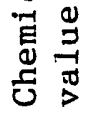

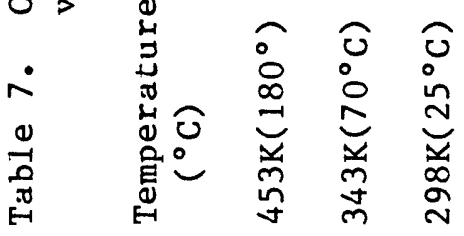


decreases with reaction time, the percent of the inorganic fraction or ash concentration increases. Regardless of the reaction time the actual amount of inorganic matter (ash) in the residue is essentially constant $(\simeq 0.29 \mathrm{~g})$. This means that the amount of soluble inorganic fraction of the sludge in solution A (not shown) is also independent of the reaction time. However, the soluble organic fraction of the sludge will increase with reaction time as shown by the gradual decrease in the weight of residue $B$. It is interesting to note that the total dissolved inorganic fraction of the sludge in solution $A$ and the amount in the product are relatively constant, even though the percent concentration in the product increased as the reaction time increased. Recovery from Solution E: The amount of product G (see Fig. 1) recovered when solution A was diluted varied somewhat with the experiment but was of the order of 15 to 20 percent of the total organic material in the original sludge. No attempt was made to optimize the yield. About 40 percent of the initial organic material went into residue $B$. Thus, on the average about 40 percent of the organic material remained in solution $E$. It was found, that evaporating the solution by heating to up to but not above $100^{\circ} \mathrm{C}$ to reconcentrate the acid, additional organic material (Product J, Figure 1) would precipitate out after a second dilution. Evidently the additional heating step causes a further reaction of the soluble organic matter with the acid to form compounds which become insoluble in dilute acid. This procedure was repeated several times to remove additional organic matter. In one experiment it was found that by repeating this procedure three times, an additional 20 percent of the organic matter in the original sludge could be removed from solution $E$. However, at the higher temperatures the acid chemically reacts with the sludge forming some $\mathrm{CO}_{2}$ and other oxidation products as indicated by a reduction of the carbon concentration in the 


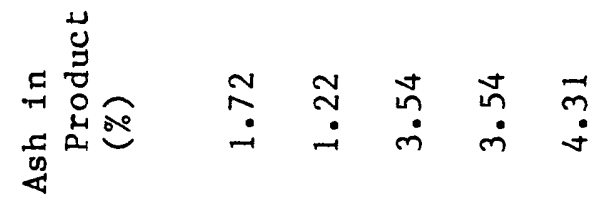

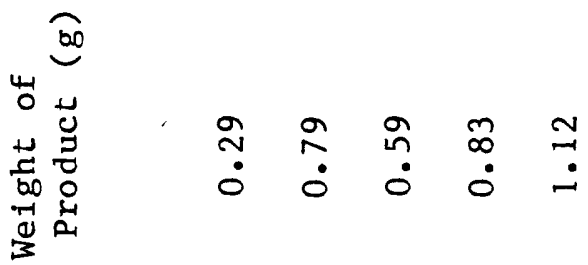

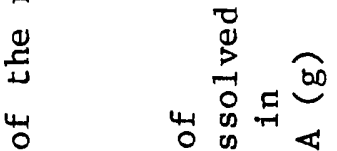

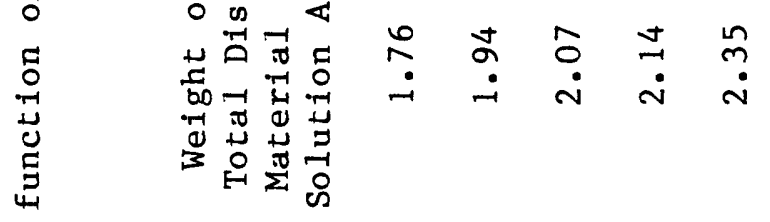

$$
\begin{aligned}
& \text { กั } \\
& 8
\end{aligned}
$$

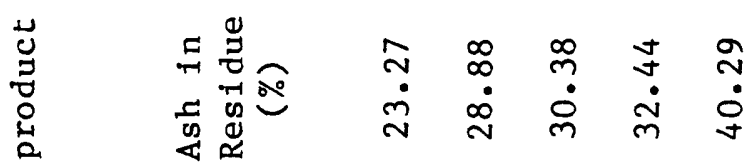

$$
\begin{aligned}
& \text { 出 } \\
& \text { 무료 }
\end{aligned}
$$

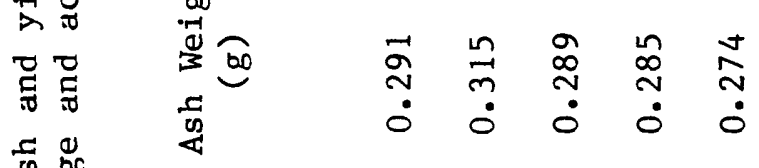

$$
\begin{aligned}
& \text { 蕓 } \\
& \text { 出 }
\end{aligned}
$$

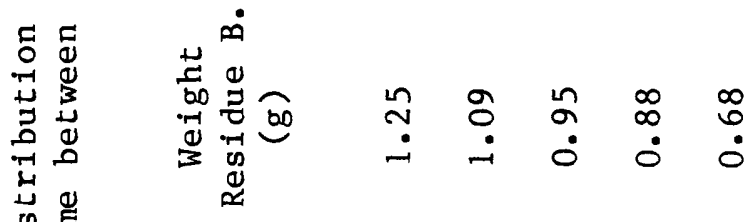

$$
\begin{aligned}
& \text { 正点 }
\end{aligned}
$$

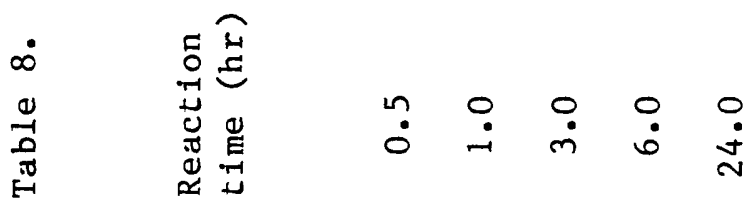


products, J, compared to the product $\mathrm{G}$.

Analyses of Inorganic Fraction of Residue B: To obtain the insoluble

inorganic fraction of the sludge, the combined sink and float residue (residue

B) was ashed. The elemental concentration of the ash was analyzed

spectrographically. The analyses of the residue ash for typical experiments performed at 25,70 , and $180 \mathrm{C}$ are shown in Table 9. [As an alternative to ashing, the residue $(\mathrm{J}-7)$, was redissolved in concentrated $\mathrm{H}_{2} \mathrm{SO}_{4}$ at $180^{\circ} \mathrm{C}$ to oxidize and remove most, but probably not all, of the organic fraction.] The most striking feature is the relatively high titanium concentration. The source of this element in the sewage sludge from a non-industrial area such as Washington, D.C is not clear. It has been suggested ${ }^{14}$ that it may be a contaminant in the $\mathrm{FeCl}_{3}$ (procured as a by-product of the paint industry) used in the sludge processing plant. However, it seems that there is too high a concentration for this to be the only major source of this metal. The lower titanium concentration in sample $\mathrm{J}-7$ is probably due to incomplete removal of the organic fraction. In the 0.01 to 0.1 percent range there are a significant number of minor elements some of which are of economic value. Extraction of some of the inorganic metals may prove to be of economic value in addition to the removal of the organic fraction as a fuel.

\section{SLUDGE-TO-ACID-RATIO}

In the initial experiments a sludge-to-acid weight ratio of $1 / 35$ to $1 / 45$ was used to ensure sufficient acid to react with all of the sludge. In order to determine the optimum amount of acid to use, a series of experiments were made at $298 \mathrm{~K}\left(25^{\circ} \mathrm{C}\right)$ and $343 \mathrm{~K}\left(70^{\circ} \mathrm{C}\right)$ as described above, using 3 grams of dried sludge " $f$ " and a reaction time of 15 minutes. Each experiment was made with a different volume of concentrated acid. The total dissolved material in the "A" solution (sample weight less the weight of insoluble residue) was 
Table 9. Spectrographic analyses of ashed residues from several experiments as indicated in footnotes.

\begin{tabular}{|c|c|c|c|c|}
\hline Sample No. & $10-100 \%$ & $1-10 \%$ & $0.1-1 \%$ & $0.01-0.1 \%$ \\
\hline${ }^{1}$ FS-6 & $\mathrm{Fe}, \mathrm{Mg}, \mathrm{Si}, \mathrm{Zn}$ & $\mathrm{Al}, \mathrm{Ca}, \mathrm{S}, \mathrm{Ti}$ & $\mathrm{Na}$ & $\begin{array}{l}\mathrm{Sb}, \mathrm{Ba}, \mathrm{B}, \mathrm{Cd}, \mathrm{Cr}, \\
\mathrm{Cu}, \mathrm{Mn}, \mathrm{Ni}, \mathrm{P}, \mathrm{K}, \\
\mathrm{Sn}, \mathrm{V}, \mathrm{Zn}, \mathrm{Zr}\end{array}$ \\
\hline $2 \mathrm{~J}-7$ & Si & $\mathrm{Al}$ & $\mathrm{Ca}, \mathrm{Fe}, \mathrm{Mg}, \mathrm{T} i$ & $\mathrm{Sb}, \mathrm{B}, \mathrm{Cr}, \mathrm{Cu}, \mathrm{Ni}$ \\
\hline $3^{3}-10$ & $\mathrm{Ca}, \mathrm{Mg}, \mathrm{Si}, \mathrm{Ti}$ & Al & $\begin{array}{l}\mathrm{Fe}, \mathrm{Mn}, \mathrm{P}, \mathrm{Na}, \\
\mathrm{Zn}\end{array}$ & $\begin{array}{l}\mathrm{Sb}, \mathrm{B}, \mathrm{Cr}, \mathrm{Cu}, \mathrm{Ni}, \\
\mathrm{Sn}\end{array}$ \\
\hline${ }^{4} J-11$ & $\mathrm{Ca}, \mathrm{Mg}, \mathrm{Si}, \mathrm{Ti}$ & $\mathrm{Al}$ & $\mathrm{Fe}, \mathrm{P}$ & $\begin{array}{l}\mathrm{Sb}, \mathrm{Cu}, \mathrm{Mn}, \mathrm{Ni}, \\
\mathrm{Ag}, \mathrm{Sn}\end{array}$ \\
\hline
\end{tabular}

1 - Experiment performed at 70 C. Residue ashed at $550 \mathrm{C}$.

2 - Experiment performed at $25 \mathrm{C}$. Residue heated in concentrated $\mathrm{H}_{2} \mathrm{SO}_{4}$ at $180 \mathrm{C}$, to oxidize \& remove organic matter. Inorganic residue analyzed.

3 - Experiment performed at 180 C. Residue ashed at $550 \mathrm{C}$.

4 - Experiment performed at 25 C. Residue ashed at $550 \mathrm{C}$. 
determined and plotted as a function of the volume of concentrated sulfuric acid.

Experiments at $298 \mathrm{~K}\left(25^{\circ} \mathrm{C}\right)$. The results of the room temperature experiments are shown in Figure 3, curve B. Replicate experiments were made to ensure the shape of the curve. As the volume or total number of moles of acid is increased, the amount of organic material dissolved in the acid increases until equilibrium is reached $\left(\simeq 60 \mathrm{~mL}\right.$ concentrated $\mathrm{H}_{2} \mathrm{SO}_{4}$ or a little more than 1 mole of acid). When 60 to $120 \mathrm{~mL}$ of acid are used, increasingly less sludge goes into solution until it reaches a minimum at $120 \mathrm{~mL}$ or a little over 2 moles of acid. When 120 to $180 \mathrm{~mL}$ of acid are used the amount of sludge going into solution again increases up to about the same maximum as observed for 60 $\mathrm{mL}$ of acid.

The maximum amount of sludge dissolved $(\simeq 1.84 \mathrm{~g}$ or 61 percent of the original sample) comprises three components, (1) protonated organic matter, (2) organic matter rendered soluble by reaction with the concentrated acid, and (3) inorganic matter. It is reasonable to assume that the true protonation curve is superimposed on a solubility curve of those organic (and inorganic) components which react with the acid to form secondary compounds. The secondary-compound solubility curve is probably relatively flat over most of the range for the acid volumes shown in the figure. Curve $B$ is therefore somewhat distorted compared to the true protonation curve. A tentative explanation of the shape of curve $B$ is given in Appendix II.

It should be noted that when $120 \mathrm{~mL}$ of acid is used (minimum protonation) a product is obtained by dilution. This indicates that secondary products also come out of solution upon dilution with water. Table 10 shows the composition of the organic material recovered by dilution of the A solution for three different volumes of acid representing the maxima and minimum in 


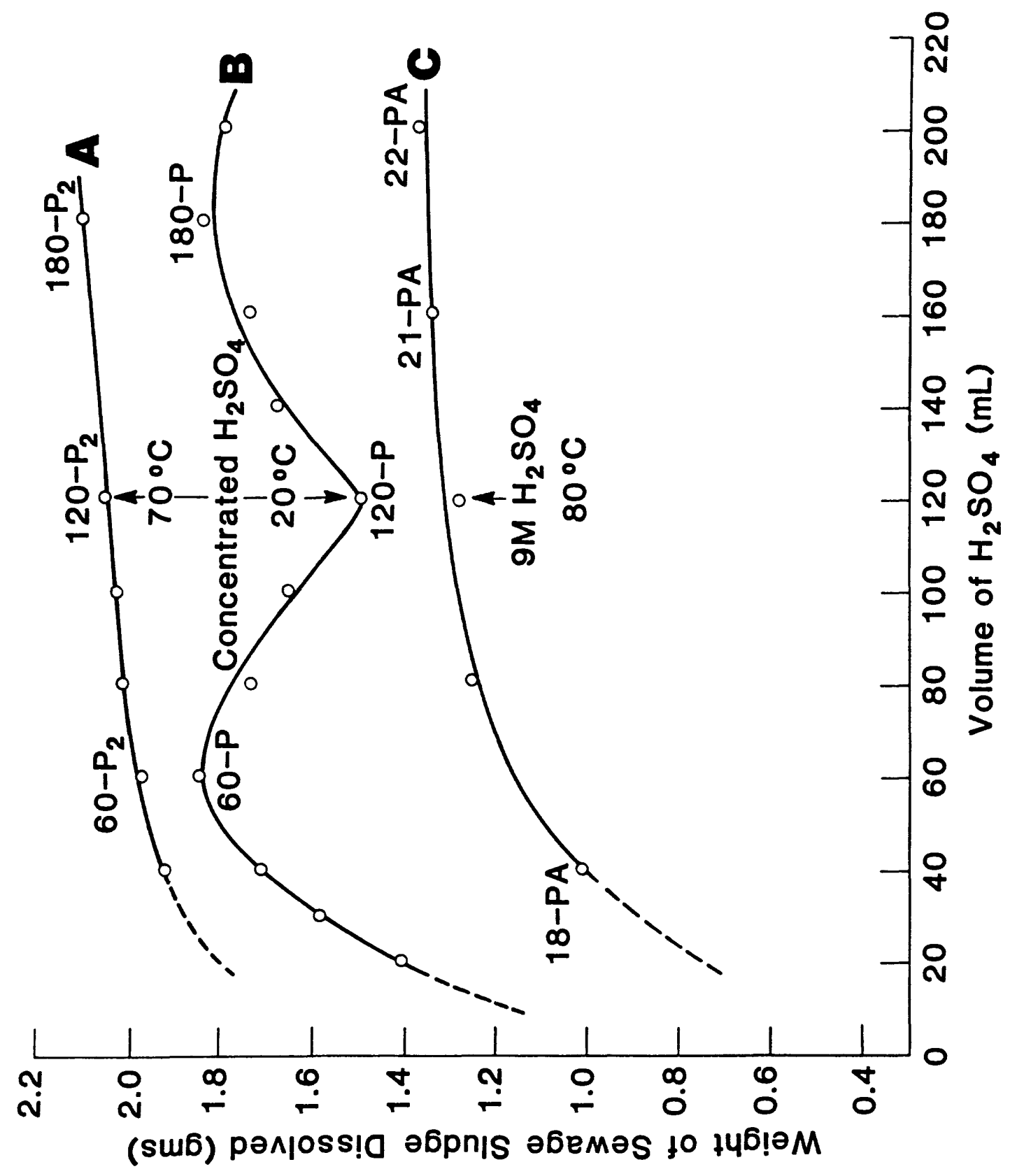




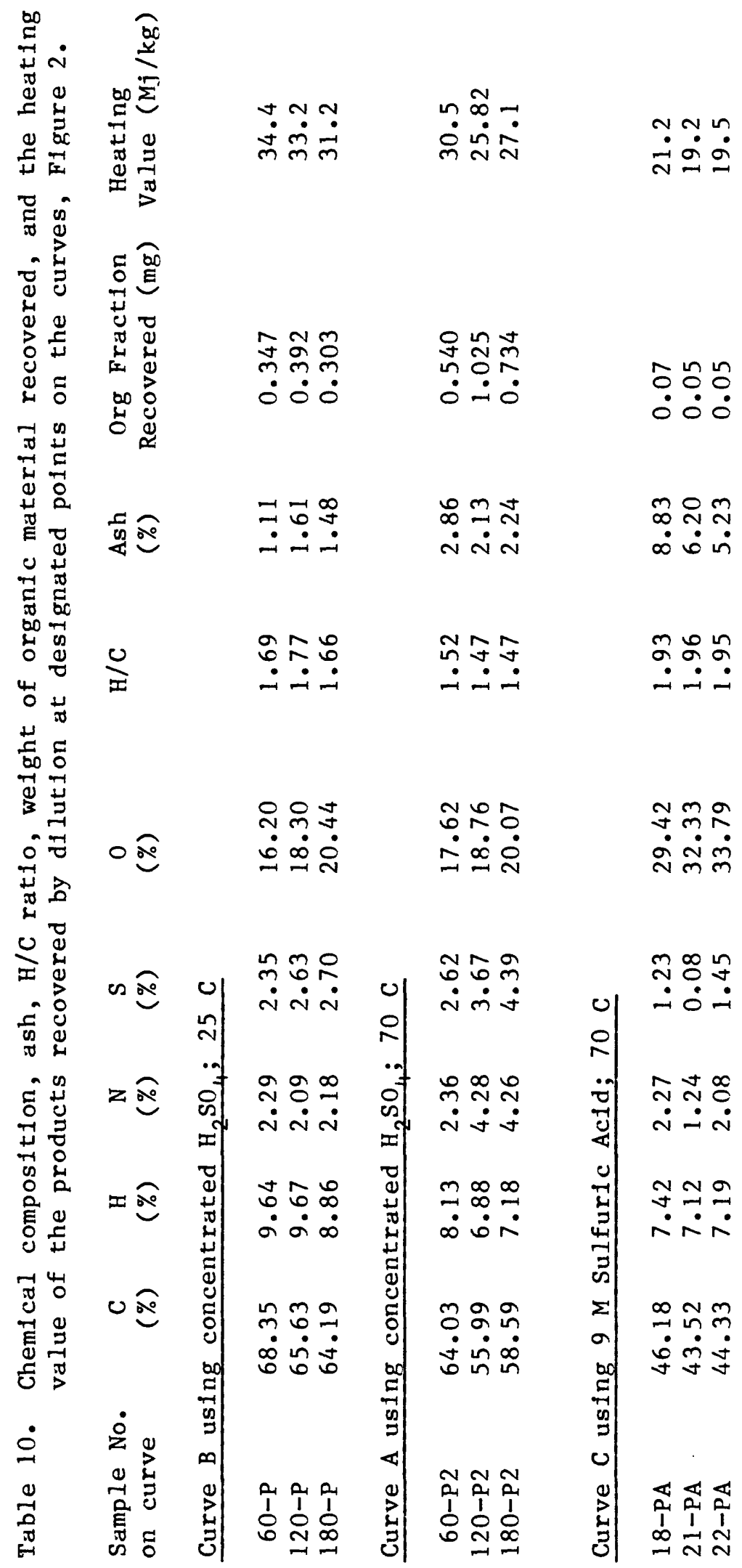


curve B. The similarity in composition was not expected and indicates no great difference in the chemistry of the product with the amount of acid used. The compositions of the deprotonated compounds and the secondary compounds are evidently not sufficiently different to make significant changes in the overall composition of the products formed with different amounts of acid. The ash concentration is low, the $\mathrm{H} / \mathrm{C}$ ratios are about the same as in the original sludge, and the heating values are very good. The sulfur concentration is higher than one might desire for a fuel, but it may be possible to reduce the sulfur with some additional work.

To determine the partition of the organic and inorganic fraction of the sludge in solution $A$ and the residue $B$, seperate experiments were made using 3 $\mathrm{g}$ of sludge and the optimum amount of concentrated $\mathrm{H}_{2} \mathrm{SO}_{4}(60 \mathrm{~mL})$. About 1.75 $\mathrm{g}$ of the sludge sample were dissolved in solution A (58 percent of sludge) and of this amount $0.33 \mathrm{~g}$ (19 percent) were inorganic material. The insoluble residue B $(1.25 \mathrm{~g})$ was analyzed to be 23 percent $(0.29 \mathrm{~g})$ inorganic and 77 percent (0.96) organic matter. Thus, a little more than half of the inorganic matter in the original sludge sample dissolves in solution A; the other half resides in the residue $B$. In summary the dissolved matter in solution $A$ is comprised of 80 percent organic (60 percent of the original organic matter in the sludge) and about 20 percent inorganic matter $(\simeq 50$ percent of the original inorganic matter in the sludge). The residue $B$ consists of 77 percent organic material (40 percent of original organic matter in the sludge) and 23 percent inorganic matter $(\simeq 50$ percent of the original inorganic matter in the sludge).

Experiments at $70^{\circ} \mathrm{C}$. When the same experiments were made at $70^{\circ} \mathrm{C}$ slightly more of the sludge sample dissolved (see Curve A, Figure 3). The sludge dissolved significantly with an increase in the volume of acid up to about 80 
$\mathrm{mL}$, and at a slower rate $(8.5 \mathrm{mg}$ of dissolved sludge/mL acid) with additional acid. The higher temperature evidently precludes significant protolysis and favors oxidation reactions. It appears that the organic material is oxidized to soluble products which gradually increase with the amount of acid used. The composition of three of the products extracted from the A solutions along the concentrated acid curve at $70^{\circ} \mathrm{C}$ (Curve A) have compositions which are not quite as good as those shown in Curve B and which reflect a somewhat lower heating value. However, the organic fraction recovered is impressively greater. This latter fact and the shape of curve A compared to curve B indicates that at the higher temperature chemical reaction with the hot acid is more pronounced than protonation.

For comparison a series of experiments were made to determine whether or not diluted $\mathrm{H}_{2} \mathrm{SO}_{4}$ can be used instead of concentrated acid to dissolve the organic material. The experiments were made at $\simeq 353 \mathrm{~K}\left(80^{\circ} \mathrm{C}\right)$, and a reaction time of 15 minutes with dilute sulfuric acid $(9 \mathrm{M})$. In dilute acid the principal ions are $\mathrm{H}_{3} \mathrm{O}^{+}$and $\mathrm{HSO}_{4}^{-}$. The curve (Curve $\mathrm{C}$, Figure 3) is similar to Curve $A$ and the quantity of acid-soluble material obtained $(\simeq 1.35 \mathrm{~g})$ is significantly lower than with concentrated acid. Although the amount of soluble material is relatively small, it consists of about 80 percent organic and 20 percent inorganic matter, i.e. approximately the same as in the experiments made at room temperaure.

The composition of three organic samples extracted from the A solutions along the dilute $\mathrm{H}_{2} \mathrm{SO}_{4}$ curve at $343 \mathrm{~K}\left(70^{\circ} \mathrm{C}\right)$ are also shown for comparison (Table 10). The composition of the products is more variable and show significant deterioration of the desirable fuel characteristics compared with the organic samples extracted from solutions along Curves A and B. Considering the relatively small amount of product obtained with the dilute 
acid extraction, and the undesirable elemental concentrations of the products as fuel compared to those obtained by concentrated acid extraction, it appears that dilute acid cannot be practically used for extraction of organic matter as a potential fuel from sludge.

\section{Summary and Conclusions}

To test the proposition that a significant fraction of the organic part of sewage sludge may be removed as a solid fuel, a number of experiments were made by reacting the sludge with concentrated $\mathrm{H}_{2} \mathrm{SO}_{4}$ at $298 \mathrm{~K}\left(25^{\circ} \mathrm{C}\right)$ following the procedure outlined in Appendix I. Some of the organic matter was rendered soluble by protonation and some by chemical reaction with the $\mathrm{H}_{2} \mathrm{SO}_{4}$. About 20 percent of the organic material in the sludge could be recovered by dilution in water. This material can be classed as a high technology fuel as it has a low ash concentration and a heating value of greater than $30 \mathrm{MJ} / \mathrm{kg}$. About 40 percent of the initial organic material reacted with the acid to form soluble compounds. About half of this material could be recovered. However, the ash concentration is somewhat higher and the heating value slightly lower compared to deprotonated product referred to above. Regardless of the relatively poorer quality, this product is still a viable fuel. The balance of the initial organic matter in the sludge is insoluble in the acid at low temperature. By reworking the insoluble residue with $\mathrm{H}_{2} \mathrm{SO}_{4}$ at higher temperatures (up to $343 \mathrm{~K}\left(100^{\circ} \mathrm{C}\right)$, a major fraction of the originally insoluble organic material can be put into solution and recovered by subsequent dilution with water. Because of the low carbon and high sulfur concentration this material has only a marginal value as a fuel, but may be used as a source of organic chemicals.

The inorganic residue was found to be high in titanium, calcium, magnesium, silicon, and aluminum. Titanium in particular appears to be 
amenable to economic recovery. In addition there are small values of silver, tin, cadmium, chromium, nickel, copper and vanadum which may be worth recovering.

It is recognized that this is a preliminary study and needs to be followed by a more detailed study to upgrade the yield of the product as a fuel and reduce the sulfur concentration. In particular it is recommended that a cost effectiveness study be made. Such a study should include removing approximately 20 percent of the organic materfal as a high technology fuel, 20 percent as a normal fuel, and about 25 percent as an organic chemical source material. These numbers are based on laboratory experiments in which about 35 percent of the initial organic matter was lost and therefore could be upgraded by improving the efficiency of some of the extraction steps. In addition, some metals may be profitably extracted from the inorganic residues. Concentrated $\mathrm{H}_{2} \mathrm{SO}_{4}$ is the only chemical used in the process, and this can be largely recovered and reconcentrated. The collective process may be economically feasible and would warrent a pilot plant study if the costeffectiveness study appears to be positive.

\section{Acknowledgements}

The authors are grateful to Dr. R. J. Gillespie of McMaster University, and to Drs. John Morgan and P. S. Aruscavage of the U.S. Geological Survey for their stimulating discussions. Thanks are also due to Dr. James Johnson, Jr. and his colleagues at Howard University for their efforts to determine the cost effectiveness of the method. 


\section{APPENDIX I}

Laboratory Procedure for Treating Sewage Sludge.

From the various experiments described in the report (see flow chart in Figure 1 for nomenclature), the following recommended procedural steps for removing organic products can be outlined.

1. Gradually mix dried sludge ( $\simeq 2.3$ percent water) with concentrated sulfuric acid (96-98 percent) in the ratio 1 gram of sludge to $20 \mathrm{ml}$ of acid while stirring at room temperature for 30 to 45 minutes.

2. Centrifuge the mixture at about $3500 \mathrm{rpm}$ until a well-defined float and sink fractions are observed. The combined insolubles are residue "B".

3. The float and the black acid solution (Solution "A") are transferred to a second centrifuge tube leaving the sink fraction. The second tube is recentrifuged to again separate the "A" solution and the float which were mixed during the pouring procedure. The "A" solution is carefully removed from the float by pouring or pipetting.

4. Distilled water is added to both the float and sink centrifuge tubes and recentrifuged. This is repeated several times until the wash water is close to $\mathrm{pH}=7.0$. The residues in each case are dried in a dessicator or freeze-dried. The float residue contains ( $\simeq 85$ percent organic matter) and the sink contains $\simeq 48$ percent inorganic matter.

5. From the volume of solution "A" determine the volume of water (see Figure 2) required to sink the product when the solution is diluted with the predetermined volume of water. After the product settles out or after centrifugation, decant the solution (solution "E"). Add distilled water to wash out acid and centrifuge. Repeat washing process until wash water is near neutrality. Dry product as above. This produce (product G) is the prime product containing over 98 percent organic matter with a high heating value. 
6. Heat solution " $E$ " between 80 and $100 \mathrm{C}$ to evaporate water and reconcentrate the acid. Keep temperature as low as possible. When the solution approaches concentrated acid ( $>95$ percent) additional organic matter will precipitate. The entire solution is then centrifuged to recover an additional product. The product is removed, washed and dried as described above yielding Product J. If desired this step can be repeated and more organic material can be recovered although the amount diminishes with each repeat operation. 
Appendix II

\section{SULFURIC ACID PROTONATION}

The reactions involved in curve $B$, Figure 3 are not entirely clear and additional experiments will have to be made before a full explanation can be made. However, a tentative explanation of the experimental data can be outlined as follows.

In those experiments in which less than $60 \mathrm{~mL}$ of acid were used, it appears that protonation increased with the volume of acid used. If (Org) is that part of the organic material in the sludge that is amenable to protonation, then for any volume of acid of less than $60 \mathrm{~mL}$ one can write

$$
\text { Org })+\mathrm{mH}_{2} \mathrm{SO}_{4} \rightarrow \mathrm{m}(\mathrm{Org}) \mathrm{H}^{+}+(1-\mathrm{m})(\mathrm{Org})+\mathrm{mHSO}_{4}^{-}
$$

where $\mathrm{m}$ is less than 1. As $(\mathrm{Org}) \mathrm{H}^{+}$is formed, the acidity of the solution decreases, and a relatively large amount of $\mathrm{HSO}_{4}^{-}$ion accumulates. Loss of acidity ultimately causes protonation to terminate. If larger volumes of acid (but less than $60 \mathrm{~mL}$ ) are used, more organic matter will be protonated and dissolve. Finally, the protonation-versus-volume of acid-curve will reach a maximum at about $60 \mathrm{~mL}$ of acld. Assuming the maximum is attained because all the organic matter that can be protonated is protonated, then, if more than 60 $\mathrm{mL}$ of acid is used, no further organic matter will dissolve. In this case the curve should show saturation with further addition of acid. However, this is contrary to the experimental data and indicates a further mechanism is involved.

At the maximum the system is undoubtedly in equilibrium, and

$$
(\mathrm{Org})+2 \mathrm{H}_{2} \mathrm{SO}_{4}+(\mathrm{Org}) \mathrm{H}^{+}+\mathrm{HSO}_{4}^{-}
$$


As the hydrogen ion concentration is extensively associated with the protonated organic matter, the acidity of system is low and less than that required for protonation. Thus, as no further protonation can occur, and the addition of more acid simply increases the acidity of the system. The $\mathrm{H}_{3} \mathrm{O}^{+}$ introduced with the additional acid will suppress the $(0 \mathrm{rg}) \mathrm{H}^{+}$. Some of the (Org) therefore again becomes insoluble. As almost $60 \mathrm{~mL}$ of acid $(\approx 1 \mathrm{~mole}$ $\left.\mathrm{H}_{2} \mathrm{SO}_{4}\right)$ was required to form the $(\mathrm{Org}) \mathrm{H}^{+}$which resulted in a reduction of acidity, it will require about the same amount of acid to increase the acidity back to that necessary for protonation to take place again. Further addition of more than about $120 \mathrm{~mL}$ of acid will thus start the protonation process again, and the curve will pass through a second maximum as is observed experimentally.

The above model explains the experimental data, but must be further checked before it can be used as a final explanation of the data. 


\section{Figure Captions}

Figure 1. Flow chart showing the steps required to obtain the various products.

Figure 2. Dilution ratio of solution "A" with water needed to produce a precipitate which floats or sinks.

Figure 3. Weight of sewage sludge dissolved as a function of the volume of concentrated $\mathrm{H}_{2} \mathrm{SO}_{4}$ mixed with 3 grams of sludge. Curves are shown for concentrated $\mathrm{H}_{2} \mathrm{SO}_{4}$ at $70^{\circ} \mathrm{C}$ (Curve A), at $25^{\circ} \mathrm{C}$ (Curve B), and for $9 \mathrm{M} \mathrm{H}_{2} \mathrm{SO}_{4}$ at $80^{\circ} \mathrm{C}$ (Curve $\mathrm{C}$ ). 


\section{References}

1. Anonymous, 1978, Sewage-sludge-how do we cope with it? Report to the Congress of the U.S., No. CED-78-152, Sept. 1978, 39 pp.

2. Bayer, E. and Kutubuddin, 1982, Low temperature conversion of sludge and waste to o11, Proceed Internat. Recycl. Recovery Energy Mater. Residues Waste, ed. Thome-Kozmiensky and J.E. Kar1, Fre1tag-Verlag Umwe1ttech, Berlin, Fed. Rep. Ger., pp. 314-318.

3. Bridle, T. and Campbell, H.W., 1983, Fuel production from sewage sludge, Proc. West Can. Water Sewage Conf., 35th pp. 195-202.

4. Donovan, J., Miller, R., Batter, T., and Lottman, R., 1981, Physical and chemical characteristics of sewage sludge, EPA Rept. 600/s2-81-242, Municipal Enviro. Res. Lab, Cincinnati, Ohio 45268.

5. Mo1ton, P., and Fassbender, A. 1983, Batte1le-Northwest sewage to fue1 of1 conversion, U.S. EPA Internat. Conf. Thermal Conversion of Municipal Sludge, Mar. 21-24, Hartford, Conn.

6. Sommers, L.E., Nelson, D. W., and Kivleis, A. W., 1984, Characterization of Sewage Sludge and Sewage Sludge-Soll, U.S. Environmental Protection Agency Report EPA-600/S2-84-046, 4 pp.

7. Wangh, A. B. and Bowling, K., 1984, Removal of mineral matter from bituminous coals by aqueous chemical leaching, Fuel processing Technology, 9, 217-233.

8. Anonymous, 1981, The determination of alkali extractable organic matter, Methods Exam. Waters Assoc. Matter (Pub 1983, U.K. Dep. of the Environment, Lond, $16 \mathrm{pp}$.

9. Vasilakos N.P. and Clinton, C.S., 1984, Chemical beneficiation of coal with aqueous hydrogen proxide/sulfuric acid solutions, Fuel, 1561-63. 
10. Gillespie, R. J. and Robenson, E.A., 1959, The sulfuric acid solvent system, in Adv. in Inorganic Chem, and Radiochem., Eds. H.J. Emetens and A. G. Sharpe, Academic Press, New York, N.Y.

11. Gillespie, R. J., and Leisten, J.A., 1954, The behavior of organic compounds in sulfuric acid, Quart. Rev. 8, 40-66, Chem. Soc. (Lond.).

12. Liler, M., 1971, Reaction mechanisms in sulfuric acid, Organic Chemistry, A series of Monographs, Academic press, New York, N. Y.

13. Giazzie, G. and Columbo, B., 1982, Characterizing fuels, J. Coal. Quality, 2, 26-28.

14. Halpern, P., World Resources, Inc., Tysons Corner, VA. private communication. 